Rupkatha Journal on Interdisciplinary Studies in Humanities (ISSN 0975-2935), Vol. 10, No. 1, 2018 Special Issue on "Interrogating Cultural Translation: Literature and Fine Arts in Translation and Adaptation" In collaboration with the Department of English, Amrita Vishwa Vidyapeetham Guest-edited by Dr. Hari M G, Amrita Vishwa Vidyapeetham, Coimbatore, India DOI: https://dx.doi.org/10.21659/rupkatha.v10n1.10 Full Text: http://rupkatha.com/V10/n1/v10n110.pdf

\title{
English Transference of Hindustani: A Pragmatic-Stylistic Study of Gulzar's Poetry
}

\author{
Pallavi Kiran \\ Senior Research Fellow, Department of Humanities \& Social Sciences, Indian Institute of \\ Technology (Indian School of Mines), Dhanbad, Jharkhand.E-mail: pallavikiran@ymail.com
}

Received September 27, 2017; Revised December 11, 2017; Accepted December 30, 2017; Published February 04, 2018.

\begin{abstract}
:
Gulzar (Sampooran Singh Kalra) is a contemporary Indian poet versing in Hindustani. Emerged during the $14^{\text {th }}$ century, Hindustani came from the Deccan representing the mix of Hindi and Urdu. It soon became a literary language and poetic communication through the Hindi-Urdu format appealed to every reader. Similarly, Gulzar makes poetry out of Hindustani colloquial speech that strikes the head and heart of the listener. However, is it the same when transferred into English? To find out the aesthetic effect of Gulzar's poetry, the present study selects two poems randomly with their English translation by J. P. Das and Rina Singh. The original and the translation are compared through a pragmatic and stylistic approach. The approach helps to locate the loss in translation without overanalysing. The study effectively brings out how the translators capture the allusiveness of Hindustani in English and makes the target readers feel the same aesthetics.
\end{abstract}

Keywords: Gulzar's poetry, Hindustani language, English translation, Pragmatic analysis, Equivalence or loss.

\section{Introduction}

Gulzar is the pen name of Sampooran Singh Kalra (18 $8^{\text {th }}$ August $\left.1934^{-}\right)$whose worldwide fame rests chiefly on his achievements as a Bollywood Lyricist and a Film Director, but "he is first and foremost a poet." (Bashir, 2013, p. 2) Indeed his poetic quality and quantity (with 12 anthologies and more than 200 lyrics (majorly lyrics-cum-poetry)) influenced the poetry scene in India since 1960s. His massive literary gamut made him earn Sahitya Akademi (2002), Padma Bhushan (2004), and recently Dada Saheb Phalke (2013) awards. Being an "Indian poet of Popular Culture," (Bashir, 2013) he writes in a language what he calls "Hindustani." His use of Hindustani falls in line yet differs in poetic sense and style from the other Indian poets such as Bulleh Shah, Harivansh Rai Bachhan, Kaifi Azmi, Nida Fazli and Amrita Pritam who broke the shackles of classical poetry tradition and followed the style of free and blank verse of their era. Interestingly, in the year 1995 Rina Singh translated his poems in English first. Later it was picked up by J.P.Das, Sunjoy Shekhar, Pavan Kumar Varma and recently by Nirupama Dutt. Although, the translations exist for the past ten years, no academic effort is yet made to evaluate them. No theoretical aim is set forth to check how far the translators have succeeded in replicating Gulzarean style in English.

(C) Authors. Published by AesthetixMS under a Creative Commons Attribution Non-Commercial 4.0 International License (http://creativecommons.org/licenses/by-nc/4.0/). 
The implicit assumption that crop up here is the untranslatability of his poetry owing to the cultural exoticism. The other assumptions like readability, target linguistic norms, accessibility, faithfulness, accuracy and equivalence has kept the translation and the translator out of focus. In this exigency, the present paper attempts to evaluate the English translation of Gulzar to check if the assumptions stand null and void or prove themselves true. Methodologically, two poems are randomly selected and within a framework of pragmatic and stylistic, the original and the translations are evaluated.

\section{Objective of the Study}

The attempts made in the study are with the objective to address to the following concerns:

i. How does Gulzar make Hindustani work for his poetry?

ii. How 'pragmatic and stylistic approach' justify the evaluation?

The following section reviews the poetry of Gulzar to highlight the features of his poetry and illustrates an example to show how he poetises with Hindustani.

\section{Reviews on Gulzar's Poetry}

Born and brought up in Pakistan, experienced the life experiences in India, witnessed the partition of the two countries, the highs and the lows in relationships, everything, and anything that cannot be called out right here, gave him his subjects for poetry. Re-energising Hindustani poetry with his huge collection of poems namely Kuch Aur Nazme (1980), Mera Kuch Saman (1994), Raat Pashmine Ki (2002), Triveni (2003), Pukhraaj (2005), Yaar Julahe (2009), Pandrah Panch Pachattar (2010), Meelo Se Din (2010), Dyodhi (2012), Pluto (2013) showcases a variety of poetic innovation. Contrary to this, he adds his multilingual ingredients to follow the time and culture. He states:

"Maine koshish kee hai ki zuban poori tarah se Hindustani rahe, jis me urdu or hindi ka mila-jula ganga jamuna mizaaj milta hai. Kahin kahin dono ki madad se aur kabhi kabhi angrezee ke istemaal se bhi baat pahuncha dene ki kosis kee hai. (I have tried to write entirely in Hindustani, which is a blend of Urdu and Hindi. At times, I have taken help from both, and sometimes I have used English to communicate the message.)" (Bashir, 2013, p.62)

This trait of code switching between Hindi, Urdu and sometimes English is a strategic poetic technique for he holds that "a living language always changes and modifies itself and one needs to represent the times in which one is writing." (Bashir, 2013, p.68-69) Hence, he evolved with the changing time and so did allow his creativity too. He states, "he belongs to Punjab, knows Bengali, reads in English and all the languages are within him and are his. He adds, what is important is how meticulous one is expressing oneself that what he communicates should not appear like patchwork." (Bashir, 2013, p.63) Thus, a multilingually diversified poet can obviously expand the horizon of poetry and so has he done. The first research on his poetry by Saba Mahmood Bashir rightly claims him as "A Progressive Poet of a Popular Culture." (Bashir, 2013, p.xiv) A propagator of Progressive Writer's Movement of the East and Imagist Movement of the West, Gulzar creates a Gulzarean style of free and blank verse with emotive and peculiar images set in the Hindi-Urdu format for the readers of the $20^{\text {th }}$ century. For example: 
Saans lena bhi kaisi adaat hai Jiye jana bhi kya rawayat hai (What sort of habit is breathing What sort of custom is living)

Koi aahat nahi badan me kahi Koi saya nahi hai aankho me

(No sound, anywhere, in the body

No vision possessed by eyes)

Paaon behis hai, chalte jaate hai

Ek safar hai jo behta rehta hai

(Insensate feet keeps walking

A traverse keeps drifting)

Kitne barso se, kitne sadiyoon se

Jiye jaate hai, jiye jaate hai

(Since years, since ages

We continue living, we continue living)

Adaatein bhi ajeeb hoti hai.

(Habits too are odd)

The colloquial words like 'saans,' 'adaat,' 'jiye jana,' 'aahat,' 'badan,' 'saya,' 'ankho,' 'paon,' 'chalte jaate,' 'safar,' 'behta,' 'barso,' 'sadiyoon,' and 'ajeeb' justify the poet's attempts to evoke a deep thought in the readers, help them to interpret the link between the language and the world, and seek to establish a literary communication. Words like 'rawayat' and 'behis' are Urdu words meaning 'custom' and 'insensate' respectively that pulls the readers to react them quickly due to their emotional baggage as well as the fact that we do not hear them that often in our conversation. Gulzar knows his audience well and hence is able to tailor his images to obtain the desired emotional response. Pavan K. Varma comments on his sense of imagery, "The uniqueness of Gulzar's verse is that it is luminescent with imagery that is startling as it is beautiful. He has the ability to juxtapose a thought with an image so powerful that a reader is literally wrenched out of his or her world." (Gulzar, 2012, p. xvi) In this regard, Gulzar gives the credit of shaping his poetic cult to T.S.Eliot, Rabindranath Tagore, Bulleh Shah, Farid, Sant Tukaram and Naamdev (Bashir, 2013, p. 122). Thus, Gulzar's poems are pragmatically driven and stylistically weaved that invites a comparative study with its English versions at the cross-cultural level and the aesthetic effect of his poetic simplicity and naturalness on the English audience. In support of this methodological approach, the following section reviews few influential poets of the Hindustani poetry and how their poems are approached in English.

\section{Reviews on Hindustani Poetry}

During the medieval India, Hindustani was the medium of expression. Tara Chand makes the following statement for the language:

"Hindustani, historically also known as Hindavi, Dehlvi and Rekhta, is the lingua franca of North India and Pakistan. It is an Indo-Aryan language, deriving primarily from the Khariboli dialect of Delhi, and incorporates a large amount of vocabulary 
from Sanskrit, Persian, Arabic and Chagatai. It is a pluricentric language, with two official forms, Modern Standard Hindi and Modern Standard Urdu which are its standardised registers, and which may be called Hindustani or Hindi-Urdu when taken together." (Chand, 1944)

Though used as the colloquial speech, the language showed high degree of emotional intensity and within no time, it became a literary language and Hindustani poetry emerged thus. The present study delves deeper to brief out how few poets who made use of Hindustani and how their English translation widen and diversify the scope of Hindustani poetry.

In the context of Hindustani poetry, "the name of Ghalib stands foremost." (Qadir, 2008, p.18) Ghalib's poetry absorbs the words and expressions of Urdu and Persian. His poems enrich the colloquialism and simplify the vocabulary of Hindustani. The subject of his poetry comes from everyday philosophy, existentialism and mysteries of life that soothes and delights the hearts of many in their moments of pensiveness or joy. Ghalib's Ghazal revised the older Ghazal conventions of expressing only 'the pangs of love' to 'talking love' (Qadir, 2008, p.22) Though his couplets are easy on the tongue and witty in a sense, translating Ghalib's poems was not considered easy. While translating the couplets of Ghalib, Ralph Russell remarks, "You are forced with the stubborn and unalterable fact that Urdu has rhyming words in plenty and English has not. [...] You are forced, then, in most cases to translate a poem knit together by a unity of rhyme into one where this kind of unity cannot be maintained." (Russell, 1968-69, p.77) Thus, sounds of the Urdu often pose difficulties for the translators. However, a linguistic evaluation can explain why it becomes easy to understand the translation shifts in making the meaning and the sense fit into a new rhyme scheme.

Hindustani, the lingua Franca of North India helped the poets of the partition period to voice the pain and agony of their region. For example, Bulleh Shah's (168o-1757) poetry occupies much of his subject from the turbulence in Punjab between Muslims and Sikhs. He wrote spiritual poetry propagating the four stages of Sufism: Shariat (path), Tariqat (observance), Haqiat (truth) and Marfat (union) that appeals to all. (Bulleh Shah, 2009) Sufi singers in India and abroad still follow his style. However, in the English translation Bulleh-Shah-made-easy, Muzzafar G. A. Ghaffar criticises the "over simplifying the meaning of the verses in order for the uninitiated or partially initiated to make sense of them; and under mixing the need for the Punjabi literacy by offering a Romanised transliteration of the verses and their English translation on top of that." (Poetic Justice, 2017) Indeed, poetry translation should not be a process of oversimplifying or under mixing of the poetic elements but the transfer of entire creative energy of the original. A linguistic evaluation can explain the oversimplification and over mixing in translation.

During upheaval and unrest in India, the Progressive Writers Movement, played a significant role in the development of Hindustani poetry. Besides, using Hindustani to inspire people through writings, preach equality and lash out at the social inequality and backwardness, it led to the unification of the art and further beautification. Among the prominent members of the movement were Sadat Hassan Manto, Ali Jawad Zaidi, Zoe Ansari, M.D. Taseer, Faiz Ahmed Faiz and many more. Among them, Kaifi Azmi (1919-2002) introduced Hindustani poetry in Bollywood. His song 'Ab tumhare hawale watan saathiyoon' still stirs up the sense of patriotism in Indians. Experiencing the menaces of communalism since childhood and the love for country since then, inclines his poetic writing. He has four anthologies to his credit namely Jhankar (1944), Akhiri Shab (1947), Awara Sajde (1974) and Iblis ki Majlis-e-Shori (1983). He verses boldly and Sajjad Zaheer refers his poems as 'simple and direct.' (Siddiqui, 2015) His poems are translated into English by Pavan Kumar Varma and is criticised by Anjum Hasan. She remarks, "Pavan Kr. 
Varma has failed to find the English language equivalents for the rhythms of Urdu" (Kidwai, 20o1) and recommends not to struggle for capturing the rhythm of the original but to look for similar rhythms in the target language. Thus, the translator should try hard to make the rhythm and resonance of Hindustani reach the English readers.

Another poet-lyricist from Delhi was Nida Fazli (1938-2016) who made most use of Hindustani to voice his separation (mostly the separation from his family during partition) and loneliness. His contribution to Bollywood was in the form of ghazal complied in his anthologies namely Safar Me Dhoop Toh Hogi, Mor Nach, Lafzo ke Phool and Ankh Aur Khawab Ke Darmiya. He writes in Hindi, Urdu, and Gujarati. Again, not much is written on the English translation of Fazli. One finds one or two translation by Komal Balraz ( Kidwai, 2001) in M. Shafey Kidwai's evaluation of the Post-Independence Urdu poetry. It seems, translation is not offered to his poems yet and hence is deprived of linguistic evaluation.

A staunch woman poet Amrita Pritam (1936-2004) from Punjab challenges the patriarchal values, redefines gender roles, and narratives assigned to women through her poetry. Defining the new femininity in the mid $20^{\text {th }}$ century, she boldly discusses the female sexuality: "Her influencing gaze at sex, her exploration of emotional and psychological nakedness and a sense of self-irony and self knowledge underwrite several of her poems." (Amrita Pritam, 2016) Sunwani while briefing out the life and work of Amrita Pritam, her place in and contribution to Punjabi literature, presents the fact that her works are translated in English, Albanian, Bulgarian, French, Polish, Russian, Spanish and all the 21 Indian languages. Nirupama Dutt, a poet, writer, translator and close friend of Pritam, translates some of her works in English. Surprisingly, the translated works are still deprived of scholarly evaluation.

Thus, we see how these poets exert peculiar influence on Hindustani poetry. They bring with them the traces of literary cultures they have been through and leave behind their own literary trails. The subjects of their poetry are mainly partition, exile, society, and the love and sorrow within. Their unique poetic style shapes the understanding of Hindustani poetry and we learn about their English translations. First, the metaphors and symbols carrying the nuances and the politeness of Hindustani pose a great difficulty to the translators. Second, it must transfer the entire creative energy importantly sound, rhythm and resonance of the poem, which otherwise makes the translation appear as over simplified or under-mixed. Third, we learn the importance of translating literary pieces immediately. Though the translations do not enjoy the high status more than the original, but the aim is to make the original available to the future generations. Fourth, is to make translation undergo an evaluation by the linguistic critics and scholars to locate the problems in translation and provide remedies for it. A linguistic evaluation authenticates the translation and makes the original reach the target readers as original as possible. Thus, the above stated facts project the reason to select Gulzar's poem and his English translation for the present study. Briefing out the poetic purposes and style of the above poets justifies how Gulzar poetises in their lineage. As a contemporary, he too exerts peculiar influence and diversifies the dimensions of Hindustani poetry by conveying his deep philosophies of life and its aspects through colloquialism. His literary worth and presence is appreciated by the good amount of English translations available. The study carries out a pragmatic-stylistic analysis of English translations and adds a linguistic dimension to Gulzar's poetry, which aims to pass down his poetic style, form and fame as a poet of Hindustani to the preceding generations. 


\section{Pragmatic-Stylistic Approach}

In poetry translation, the contemporary approaches discard the traditional evaluation at the lexical, syntactical and semantical levels that passes the translation as good without studying the methodological problems from a non-empirical point of view. It now emphasises on all the elements of the poetic system that makes a piece of writing a poem in original as well as in target language. In this context, Ovidiu Matiu in the study "Translating Poetry: Contemporary Theories and Hypotheses" explains how to locate the problems and provide remedies to it in poetry translation through three different hypotheses. The first hypothesis is the 'initial codes' that asserts to "preserve the metaphors, to the lexical registers, to the style, to the "prosodic code" that the poet uses in his work." (Maitu, 2008, p.130) 'Communication' is the second hypothesis asserting on "all those who communicates are translators" (Maitu, 2008, p.131) and translation is a 'tripartite process' involving three participants: transmitter (poet) - translator - target audience. Moreover, communication through translation follows 'bilingual synonymy' i.e. lexicalgrammatical synonymy in two languages." (Maitu, 2008, p.132) Third hypothesis is the 'thorough analysis of the source language text' that asserts on deciphering the semantic code and the formal code of the original text; rendering the same elements at all the levels and establishing an emphatic relationship between the poet and the target audiences.' (Maitu, 2008, p.133)

Thus, considering the above hypotheses directs to a pragmatic and stylistic approach. The first two hypotheses cover up the pragmatic and the last covers up the stylistics of the texts. This proves that a pragmatic analysis must be followed by a stylistic analysis. Moreover, unlike the earlier evaluation, pragmatic-stylistic approach covers up all the elements of the original and the translation without over analysing. Playing up on these facts, the present study proposes to carry on the comparison and contrast of Gulzar's Hindustani poetry in English through the pragmaticstylistic approach.

\section{Corpus of the Study}

The study is essentially text based and data driven. It selects two poems randomly and places side by side for the evaluation. Each line is tested to find out the mode of translation of translator besides their pragmatic and stylistic features.

\section{1. 'Faasla'/ 'Distance'}

The first poem 'Faasla' (Gulzar, 2002, p.16) and its English translation by J.P.Das 'Distance' (Gulzar, 2003, p. 34-35) is examined to demonstrate how the translator eschews to be genuine.

\section{Faasla}

Takiye pe tere sar ka wah tippa pada hai, pada hai

Chaddar me tere jism ki wah saundhi si khusboo

Haantho me mehakta hai tere chehre ka ehsaas

Maathe par tere hoontho ki mohar lagi hai

Tu itni kareeb hai ki tujhe dekhu toh kaise

\section{Distance}

The pillow flaunts

the impression

you left behind, when your head

rested on it.

The bedsheets

still retain 
Thodi si alag ho toh tere chehre ko dekhu. the fragrance

of your body.

\author{
My hands tingle \\ at the memory \\ of your touch. \\ My forehead carries \\ the seal of your lips. \\ How can I see you \\ when you are \\ one with me? \\ Move away a bit, \\ so that I can \\ hold your face \\ in my eager eyes.
}

The poem has emotive images registering Gulzar's joy of kinship with her beloved in a colloquial tone. The first part of the poem details out the minuteness that reminds the poet of her presence in her absence. In an ironical tone, the poet urges her to free him of her memories so that he can focus on other things. In this regard, 'Faasla' is used as a metaphor, its equivalent "Distance" seems to succeed in conveying the reminiscences of his events, and emotions in one go of reading. The poem is intense in both the languages with some conflict. The pragmatics and the stylistics features are studied as under:

\subsubsection{Pragmatic features}

The phrases 'sar ka woh tippa,' 'jism ki woh saundhi si khusboo,' 'chehre ka woh ehsaas,' 'hoontho ki mohar' have the equivalents 'impression you left behind', 'fragrance of your body', 'memory of your touch', and 'seal of your lips' respectively. Although, they give the English verse a close defined sense but seems less open to reference than the original. 'Sir ka woh tippa' signifies the image of an accessory worn by married women mostly in India. 'Tippa' is a Bangla word meaning 'red bindi' that enhances woman's attractiveness and appeal. According to Hindu tradition, a married woman wears a 'red' coloured bindi. However, with the change in fashion and custom, even girls wear a Bindi of different colors. Gulzar stirs up his imagination with 'tippa' that reminds him of the delights of togetherness with his darling. The translation misplaces the nuance of 'tippa' as well as the intended meaning. The equivalent drawn is "pillow flaunts the impression you left behind, when your head rested on it" instead of 'tippa' is an instance of over translation. In translation, to retain the cultural words saves cultural loss and reflect the brevity of the original. 
Likewise, the next metaphorical phrase 'jism ki woh saundhi si khusboo' has an adjective 'saundhi si.' It is a Hindi word, which implies to the olfactory perception of soil after the rainfall. The image connotes that the poet finds pleasure in her bodily scent and compares it to pleasurable smell of earth after rain. In translation, the image of 'saundhi si' is deliberately dropped as Das seems to capture the poetic flow of the poem. The equivalent 'fragrance' is an inappropriate register that he possibly thought, will cover up the cultural nuance but fails altogether. However, the idea of scent/fragrance is conveyed in the next phrase in the third line "haantho me mehakta hai tere chehre ka ehsaas." The first image 'haantho me mehakta' is a construction of true physical affection where the poet can smell his beloved's scent still. Although thinking back of a smell is usually hard, but her love makes him recall the distant memories in an emotionally rich details. The connotation is again not preserved nor is translated word-to-word ('your smell in my hand') owing to the fact that it may distort the poetic rhythm and appear as an over translation. Further, the addition of pronoun 'my' is not required; the belongingness of the poet is quite understood. The next image 'chehre ka ehsaas' reminds Gulzar of her charm, radiance, and elegance as the signalling device that invites him to come close to her. The estimation 'my hands tingle at memory of your touch' appears well drawn in one go of the reading but the objective image of face is misplaced and 'memory' is an addition to keep the translation close to the original. Das understands that capturing the allusiveness of Hindustani is difficult, therefore, he skilfully uses 'tingle' (to have a sensation) to match the connotative meaning of sensation in the original. Although 'tingle' overlaps the main picture of her face and shifts the romantic effect on the phrase 'touch of memory,' the flow of context remains intact.

Images in line 4, 'maathe par tere hoontho ki mohar' have two pictures. 'Maathe' or 'forehead' feels the most affection of love. A kiss on the forehead suggests an unconditional love and care that does not expect or need a reply. 'Hoontho ki mohar' or 'seal of lips' is a metaphorical picture of his beloved's kiss. This shows the form of emotion she experiences for him. 'Mohar' is a Hindi word, which means a seal. It depicts the analogy between the kiss mark of her lips coated with lipstick and the wax used as stamp to seal the confidential stuffs. The poet conveys her intentions to abide by their dedication to each other. The line is literally translated, 'my forehead carries the seal of your lips' and shows no deviation except the addition of the pronoun 'my.'

Towards the end of the poem, line 5 and 6 is a transition in the tone where Gulzar initially pictures his fantasies about her and now sounds romantic. The phrase 'tu itni kareeb hai, tujhe dekhu toh kaise' implies that he cannot see her expressions while she hugs him. Hugging actually is a form of non-verbal communication that makes the spouse interact with each other and connects them at the deepest level. Therefore, Das equates 'itni kareeb' with 'one with me' signifying their closeness with each other where he cannot see or feel anything apart from her. The next phrase 'tujhe dekhu toh kaise' has the estimation 'How can I see you,' suggests that while hugging she keeps her face on his shoulder and hence he cannot see her expressions.

In the last line, he asks her to 'move away a bit/ thodi si alag' to see and feel her gestural love and the translation is literal. Again, the literal estimation of 'tere chehre ko dekhu' can easily captures the allusive beauty of her, her love and compassion for him. However, Das over translates, 'hold your image in my eager eyes' and takes it away from the original.

\subsubsection{Stylistic features}

i. The lines are not divided into stanzas in original except the two lines at the end separated by a line gap. Unlike this, the translation has four stanzas where each translated line forms a paragraph. The third and the fourth paragraph of the last two lines have been merged into one paragraph. 
ii. Both the poems are written as a whole and in free verse. There is no rhyme scheme. The original verse form has six complete lines, but the translation has split the cables and it counts to 21 line poem.

iii. There is only one punctuation mark, i.e. comma in the first line after 'tippa' to provide a very brief pause. The next word 'pada hai' conveys the weight and information at the same time. The image of 'tippa' takes him into the flashbacks of their pleasurable bedtime delights. There is no other punctuation mark to provide a check on the reader's speed. Unlike the original, the translator puts a comma in the first line after 'behind' and shifts the weight and concern on the image of 'head' that rested on the pillow. This tends to lose the image of 'tippa.' Again the last comma is used after 'a bit' to emphasis on the poet's feelings and adds meaning to the phrase 'hold in my eager eyes.' The translation makes use of full stop five times to show the completion of one complete thought unlike the original. This is done deliberately to accord with the original flow of the poem. The question mark in the second last paragraph is an deliberate attempt to match the interrogative word 'kaise.' It is to be noted that there is no interrogation by the poet even if he use the word 'kaise'(how) and hence he does not use the punctuation of question mark. Contrary to this, question mark in translation seems to seek an answer.

iv. Both the poems have one instance of alliteration: 'maathe par tere hoontho ki mohar' and 'eager eyes.'

v. Word classification:

\begin{tabular}{|c|c|c|c|c|c|}
\hline Nouns & Pronouns & Verbs & Adverbs & Adjectives & Prepositions \\
\hline $\begin{array}{l}\text { Takiye, Sar, } \\
\text { Tippa, } \\
\text { Chaddar, } \\
\text { Jism, } \\
\text { Khusboo, } \\
\text { Kareeb, } \\
\text { Chehre, } \\
\text { Maathe, } \\
\text { Hoontho, } \\
\text { Mohar, } \\
\text { Ehsaas, } \\
\text { Haantho. }\end{array}$ & $\begin{array}{l}\text { Tere } \\
\text { Tu } \\
\text { Tujhe } \\
\text { Wah }\end{array}$ & $\begin{array}{l}\text { Pada } \\
\text { Mehakta } \\
\text { Dekhu }\end{array}$ & $\begin{array}{l}\text { Saundhi si } \\
\text { Thodi si }\end{array}$ & Itni & $\begin{array}{l}\text { Pe } \\
\text { Ka } \\
\text { Hai } \\
\text { Me } \\
\text { Toh } \\
\text { Ho } \\
\text {-si }\end{array}$ \\
\hline $\begin{array}{l}\text { Fragrance, } \\
\text { memory, } \\
\text { touch, seal, } \\
\text { pillow, } \\
\text { impression, } \\
\text { head, } \\
\text { bedsheets, } \\
\text { body, } \\
\text { forehead, }\end{array}$ & $\begin{array}{l}\text { I } \\
\text { you } \\
\text { my } \\
\text { your } \\
\text { me }\end{array}$ & $\begin{array}{l}\text { Flaunts, left, } \\
\text { rested, tingle, } \\
\text { see, move, } \\
\text { hold }\end{array}$ & $\begin{array}{l}\text { Away, } \\
\text { Retains }\end{array}$ & $\begin{array}{l}\text { Eager, } \\
\text { bit }\end{array}$ & $\begin{array}{l}\text { So } \\
\text { Are } \\
\text { of }\end{array}$ \\
\hline
\end{tabular}




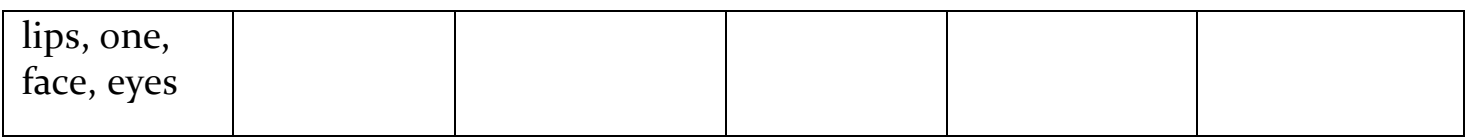

The table clearly shows the sorting of words in two languages. Hindi has a sentence structure of Subject-Object-Verb while English's sentence structure is Subject-Verb-Object. The difference in numbers of the lexical items is seen as the addition of self-references used by the poet and the translator.

Based on the above discussion, the following is an alternative translation that covers up all the shortcomings.

\section{Distance}

The pillow has the bindi of your

forehead, down there.

The petrichor smell of your body in the bed linen,

hand sentience the aroma of your face, forehead has your lip's stamp on it.

You are so close to me, how can I see you?

Move away slightly so that I can see your face.

The above translation directly renders the thought of the poet while the previous translation seems to transfuse some new spirits into it.

\section{2. 'Adaat'/ 'habit'}

The paper further illustrates the pragmatic-stylistic features of Gulzar's another randomly selected poem 'Adaat' (Pukhraaj. 84) and 'habit' (Splinter. 8o) translated by Rina Singh. The poem reads as follows:

Adaat

Saans lena bhi kaisi adaat hai

Jiye jana bhi kya rawayat hai

Koi ahaat nahi badan me kahi

Koi saya nahi hai aankho me

Paaon behis hai, chalet jaate hai

Ek safar hai jo behta rehta hai

Kite barso se, kitni sadiyoon se

Jiye jaate hai, jiye jaate hai

Adaatein bhi ajeeb hoti hai

\section{Habit}

Breathing is habit

living a ritual

There is no sound in the body

no shadow in the eyes

My feet are tired

yet I keep on walking

on this road

an endless journey.

For years

for centuries

we have been living

We go on living

we go on living 


\section{Habits are so strange}

With the literal translation, Singh tries to accord with the thoughtful poem of Gulzar. He questions the existentialism of human life with the metaphor of 'adaat.' "Existentialism focuses on the question of human existence and the feeling that there is no purpose or explanation to the core of existence." (Existentialism, n.d) Thus, living is presented as the ritualized action of human behaviour. The translation shows major displacements. The pragmatic-stylistic features are discussed as follows:

\subsubsection{Pragmatic features}

The very title of the poem 'adaat' or 'habit' attribute its literal meaning in the context of human living. The phrase 'saans lena bhi kaisi adaat hai' hints at the connotations of breathing as a habit. The negativity is reinforced with the interrogative word 'kaisi.' However, this gloomy feeling is generalised when translated i.e. 'Breathing is habit.' The second line 'jiye jana bhi kya rawayat hai' again hints at the negativity one holds in living a life as a mere convention. The translation misses the sarcastic and ironical tone of the original in 'living a ritual.' Thus, in trying to capture the simple allusiveness of Gulzar and Hindustani, Singh misses the depth and emphasis of Gulzar in questioning his living and breathing. Nevertheless, she retains the faithfulness at word level. For instance, "saans lena/ Breathing; adaat/ habit; jiye jana/ living; rawayat/ ritual," denoting the existentialism in human life.

In the next stanza, the phrases and the images are translated literally and there is no shift of form at the word level. In a sarcastic tone, the phrase suggests how poet feels lost in his life: "koi ahaat nahi badan me kahi/ koi saya nahi hai aankho me." The phrase 'koi ahaat nahi' hints at the absence of any communication i.e. the feeling of being dead inside is felt, as if someone has removed the content of chest and left a gaping void where there is nothing left but a painful, sucking black hole. The phrase "koi saya nahi hai aankho me" acknowledges the feeling of selfloathing and hopelessness. 'Saya' means shadow but in the present context, it refers to a bleak outlook of person who is convinced that nothing will ever get better in his/her life. The literal translation, "there is no sound in the body/no shadow in the eyes" fails to produce the paradoxical and sarcastical effect and tone giving a generalised effect. The emotive gravity that 'saya' and 'ahaat' carries is not felt with 'sound' and 'shadow.' Singh probably misses to understand that the literal equivalents cannot evoke the same feel of persistent sadness of the poet by the English readers. The hard questioning of Gulzar about one's living is what the target readers need to feel. The translator needs to understand that English is a synthetic language that relies on inflectional morphology. Singh's effort to capture the allusiveness of Gulzar is evident in her use of present perfect sentences.

The next paragraph contains words with heavy connotative values are not translated consistently. The phrase 'paon behis hai/ chalte jaate hai' suggests how life is being lived with a routine pattern, with no fire to attain anything and no destination to reach. 'Paon behis hai' literally states the insensate feelings in the leg. It connotes to emotional numbness one feels. Thus, the ironical phrase 'chalet jaate hai' suggests identity crisis where human beings are living their life against the existential philosophy. The line 'ek safar hai jo behta rehta hai' refers to the existentialism. 'Safar' is the metaphorical image denoting life as a journey of joys and hardships, celebrations and heartaches. Life's gradual unfolding is what Gulzar writes metaphorically "behta rehta hai" referring to an endless journey that moves forward with or without you. It never stops for anyone. The translation does not approximate with the original context and is simply paraphrasing: 
Paon behis hai, chalte jaate hai

Ek safar hai jo behta rehta hai
My feet are tired

yet I keep on walking

on this road

an endless journey.

'Tired' seems to distort the meaning of "behis." In Hindi it means 'gaatiheen' (motionless) or 'lachaar' (helpless) which has an equivalent words in English i.e. dead, rest, forlorn, powerless, stagnant, immobile, motionless etc. From the context's point of view, the most appropriate word is 'insensate' which means 'devoid of feeling and consciousness.' 'Insensate feet' somewhat triggers the emotion of the original. Further, the addition of first person singular pronouns ' $I$ ' and 'my' gives the English readers a sense of it being the poet's monologue, which actually is not. The poet is not the character within the original poem; he only serves as an unspecified, uninvolved and unnamed narrator conveying information throughout the poem. It is a pointer to the human earthly living, in general. Further, the metaphors 'safar' and 'behta' is not translated with their sense 'on this road' and 'an endless journey' respectively and loses the emotive aspect of the original. A more effective rendering is 'a traverse' for 'safar', which means 'travel across or through' the life's path.' Similarly, 'drift' is an appropriate equivalent that serves the purpose of the poet for the verb 'behta.' The characteristics of 'behta' or flowing relates to air or water or light that possesses the quality of travelling to any place on earth, be it the longest or the farthest, even or rough surface, it just flows across and drifts all that comes on its way. Hence, life too drifts away people in its flow with its current. The entire phrasal line can be translated as:

$$
\begin{array}{ll}
\text { Paon behis hai, chalte jaate hai } & \text { Insensate feet keeps walking } \\
\text { Ek safar hai jo behta rehta hai } & \text { A traverse that keeps drifting. }
\end{array}
$$

The following paragraph clearly indicates how, over the huge span of time suggested with 'kitne barso se, kitni sadiyoon se/jiye jaate hai, jiye jaate hai,' life is being lived in an unobserved, hypothetical and speculative way. Repetition reinforces the key message of existential crisis. For instance, 'kitne' in 'kitne barso se/ kitni sadiyoon se' hints to the life's irony where time is said to have the massive force to change everyone and everything, yet it cannot sweep away the existential crisis in humans. 'Barso' and 'saadiyoon' are synonymous that stands for the span of time for earthly living of humans. The fact is evident in the repetitive phrase, 'jiye jaate hai, jiye jaate hai.' Singh too uses synonyms i.e. 'years' and 'centuries' to match the context and flow of the original. The repetitive phrase 'we go on living' hints at how humans are doing the same unsatisfying things (keeps on living) time after time and are more prone to dwell on the negative emotions that makes them succumb to it. Singh makes an addition of third person pronoun 'we' in the repeated lines to keep up the poet's generalised ideas, opinions and thoughts bearing the implicit emotional and psychological suggestion in relation to the poet and his message. There is no communication snag for the English readers.

The final line emphasises on the peculiar nature of habits. In the phrase 'adaatein bhi ajeeb hoti hai,' 'adaat' here suggests how the human beings feel overpowered by the habit of existential crisis. It leads to despair and feeling that there is no way out. The translation is literal, 'habits are so strange,' where 'so' is added to the heighten the degree of the peculiar nature of habits. 


\subsubsection{Stylistic features}

i. The two poems appear different in structural pattern. The original has four couplets and the last line (carrying the crux of the poem) is separated. While the translator divides the poem into six stanzas, keeping the last line separated to match the original.

ii. The original poem is written in free verse with some rhyming pattern. It has an end sound of $/ \mathrm{t} /$ and $/ \mathrm{h} /$ in line 1 (adaat hai), $/ \mathrm{h} /$ in line 3 (hai), /ae/ in line 7 (se), /h/ in line 8 (hai) and lineg (hoti hai) forms the couplets that rhymes and serves as the backdrop from which the ideas and imagery flow. The strategy of juxtaposed images is followed to make the readers feel the emotions. For example, 'saans lena'/ adaat hai,' 'jiye jana/ rawayat hai,' 'ahaat nahi/ badan me,' 'saya nahi/aankho me,' paaon behis/chalet jaate,' 'safar hai/ behta rehta.' They carry the ironical messages of human existentialism. Unlike the original, there is no signal of end rhymes, which indicates Singh has attempted to convey the message and meaning through appropriate equivalents and makes no effort to retain the sound beauty.

iii. The original poem has many sounds that have a repetition and contributes to the pleasure of the reader. The sound of ' $k$ ' in 'kaisi' (line 1), kya_(line 2), kahi (line 3), koi (line 3, 4) and kitne_(line 7) and the sound ' $j$ ' in jiye (line 2), jana_(line 2), jiye (line 8), and jaate(line 8) serves as a commentary or a static point against which the rest of the poem develops. The translation has two repetitions: 'for' in $4^{\text {th }}$ stanza and the lines repeated in $5^{\text {th }}$ stanza: 'we go on living/ we go on living.'

iv. Further, the repetitive words like 'koi', 'nahi', 'adaat' and the phrase 'jiye jaate hai' is a purposeful way to convince the readers of the ideas of existentialism of life. Similarly, Singh repeats the word like 'no', 'habit', 'breathing', and 'living.'

v. Further, the repetition of preposition like 'bhi' (also), 'hai' (have), 'se' (from) designates assertion of their direct object of the verb. For example, 'bhi' (line 1) indicates the verb of 'saans lena.' Again, in line 2 it indicates 'jiye jana,' in line 9 it denotes 'adaatein.' Similarly, 'hai' in line 1, 2, 4, 5, 6, 8 and 9 indicates 'adaat,' 'rawayat,' 'saya,' 'behis,' 'chalte jaate,' 'safar,' 'behta rehta,' 'jiye jaate,' 'ajeeb hoti' respectively. Preposition 'se' in line 7 indicates 'barso' and 'sadiyoon' determining the time. They not only link the diverse ideas together in the poem but also add to the rhythm and provide a more mysterious point of emphasis, clarity, implications and emotional issue.

vi. The above-discussed features of repetition are not present in the rendering. Yet, one can find the repetition of '-ing' that have an incantatory effect on the poem. '-ing' is a suffix used to make one of the inflected forms of English verbs as a present participle, as gerunds and sometimes as an independent noun or adjective. For example, 'breathing' in line 1 is a gerund verb in present continuous tense to accord with the original. This depicts the situation of breathing and living as temporary. Additionally, 'no' is repeated to express the deep feelings to maintain the rhetorical effect of line 8 in the original poem. In the fifth paragraph 'We go on living' add stress on the existential view of human living. This takes the two poems close in terms of equivalence in meaning and unifies the idea of existential living. 
vii. Word classification:

\begin{tabular}{|c|c|c|c|c|c|}
\hline Noun & Pronoun & Verb & Adverb & Adjectives & Prepositions \\
\hline Saans & & Lena & ajeeb & Kaisi & Bhi \\
\hline Adaat & & Jiye & & Куа & Hai \\
\hline Rawayat & & Jana & & Koi & $\mathrm{Me}$ \\
\hline Ahaat & & Chalet & & Kahi & Se \\
\hline Badan & & Jaate & & Ek & \\
\hline Saya & & Behta & & Behis & \\
\hline aankho & & Rehta & & Kitne & \\
\hline Paon & & & & Kitni & \\
\hline Safar & & & & & \\
\hline Barso & & & & & \\
\hline sadiyoon & & & & & \\
\hline habit & My & Living & & Endless & Is \\
\hline ritual & I & walking & & tired & in \\
\hline sound & we & go & & & are \\
\hline shadow & & & & & on \\
\hline body & & & & & for \\
\hline eyes & & & & & \\
\hline feet & & & & & \\
\hline tired & & & & & \\
\hline road & & & & & \\
\hline journey & & & & & \\
\hline years & & & & & \\
\hline centuries & & & & & \\
\hline strange & & & & & \\
\hline
\end{tabular}

In the comparison, the Singh uses less nouns, verbs and adjectives and suggests that the translation does not mimic the original.

Based on close pragmatic-stylistic analysis of the poem, within the aspect of communicative function the poem is alternatively put as under:

\section{Habit}

What sort of habit is breathing

What sort of custom is living 
No sound, anywhere, in the body

No vision possessed by eyes

Insensate feet keeps walking

A traverse keeps drifting

Since years, since ages

We continue living, we continue living.

Habits are too perplexing.

The interrogative sentences are kept interrogative in order to maintain the degree of emotional effect on the English readers. The rhyming pattern is taken care of which evolves psychological response in addition. The only changes brought about are the changes in equivalent words for a more appropriate rendering. Rest nothing is altered at the pragmatic and stylistic level.

\section{Conclusion}

To conclude, the present study compares Gulzar's two randomly selected poems and its English translation by J.P.Das and Rina Singh respectively. With a careful comparison of the original and the translation at the pragmatic and stylistic level, the discussion projects a remarkable degree of dissimilarity. Though, the basic reading experience of Hindustani poetry is impossible to recapture in translation, J. P. Das renders it quite close to the original. The analysis observes instances of self-references in the translation strategy of Das. While Rina Singh's rendering is too literal that fails to capture the brevity and the sound beauty of the poem in English. Her translation appear mere paraphrasing that made her miss the aesthetic feel and effect of the original. Working with Hindustani and English, translators not only have to choose between free or literal translation, but also make strategic moves to deal with the allusive nature of Hindustani and the inflectional morphology of English. Thus, pragmatics and stylistic helped to locate the translation shifts and proved a complete legitimate tool to evaluate the translations without overanalysing. The approach is effective to bring out the value and belief system of Gulzar and make the English readers feel the Hindustani aesthetics.

\section{References}

Existentialism - By Branch / Doctrine - The Basics of Philosophy. n.d. Retrived 14 Jan, 2016 from http://www.philosophybasics.com/branch_existentialism.html

"Amrita Pritam: Sexual Politics and Publishing in Mid $20^{\text {th }}$ Century India." (2016, February 25) Retrieved October 23, 2017 from http://www.vidaweb.org/amrita-pritam-sexual-politics-and-publishing-in-mid2oth-century-india/

"Poetic Injustice." (2001, June 17). The Hindu: Online Edition of India's National Newspaper Retrieved October 23, 2017 from http://www.thehindu.com/2001/o6/17/stories/1317017n.htm

Alam, M.B. (January 01, 2017). "How to read Bulleh Shah." Retrieved October 23, 2017 from https://www.dawn.com/news/1305772 
Bashir, S. (2013). I Swallowed The Moon: The Poetry Of Gulzar. Noida, New Delhi: HarperCollins India.

Chand, T. (1944). "Medieval Language and Literature of India." In The Problem of Hindustan.i Allahabad, Uttar Pradesh: Indian Periodicals.

Das, J.P and Singh, Rina. (2003). Splinter and Other Poems. New Delhi: Rupa\& co.

Gulzar. (2002). Pukhraaj. New Delhi: Rupa\& co.

Kidwai, M. Shafey. (Sept-Oct, 2001). "Post-Independence Urdu Poetry: the Indian Panorama." Indian Literature. Vol.45. No.5 (205). New Delhi: Sahitya Akademi. p.19-33.

Maitu, Ovidiu. (2008). 'Translating Poetry: Contemporary Theories and Hypotheses.' Professional Communication and Translation Studies. 127-134

Qadir, Abdul. (27 February, 2008). "Ghalib as a Poet.” Famous Urdu Poets and Writers. New Delhi: Seemant Prakashan.

Russell, Ralph. (1968-69). “On Translating Ghalib.” Mahfil. Asian Studies Centre: Michigan State University. p. 71-88.

Siddiqui, M.A. (2015, August 27). "A poet, a revolutionary." Retrieved October 23, 2017 from http://www.thehindu.com/features/friday-review/a-poet-a-revolutionary/article7586498.ece 